STUDI

FRANCESI

\section{Studi Francesi}

Rivista quadrimestrale fondata da Franco Simone

170 (LVII | II) | 2013

Varia

\title{
Laster im Mittelalter. Vices in the Middle Ages, Edited by Christoph Flüeler, Martin Rohde
}

\section{G. Matteo Roccati}

\section{(2) OpenEdition}

1 Journals

\section{Édition électronique}

URL : https://journals.openedition.org/studifrancesi/2997

DOI : 10.4000/studifrancesi.2997

ISSN : 2427-5856

Éditeur

Rosenberg \& Sellier

\section{Édition imprimée}

Date de publication : 1 juillet 2013

Pagination : 430

ISSN : 0039-2944

\section{Référence électronique}

G. Matteo Roccati, « Laster im Mittelalter. Vices in the Middle Ages, Edited by Christoph Flüeler, Martin Rohde », Studi Francesi [En ligne], 170 (LVII | II) | 2013, mis en ligne le 30 novembre 2015, consulté le 02 février 2023. URL : http://journals.openedition.org/studifrancesi/2997 ; DOI : https://doi.org/10.4000/ studifrancesi.2997

Ce document a été généré automatiquement le 2 février 2023.

\section{(c) (†) $\odot$}

Creative Commons - Attribution - Pas d'Utilisation Commerciale - Pas de Modification 4.0 International - CC BY-NC-ND 4.0

https://creativecommons.org/licenses/by-nc-nd/4.0/ 


\title{
Laster im Mittelalter. Vices in the Middle Ages, Edited by Christoph Flüeler, Martin Rohde
}

\author{
G. Matteo Roccati
}

\section{RÉFÉRENCE}

Laster im Mittelalter. Vices in the Middle Ages, Herausgegeben von / Edited by Christoph FLÜELER, Martin ROHDE, Berlin - New York, Walter de Gruyter, 2009 («Scrinium Friburgense. Veröffentlichungen des Mediävistischen Instituts der Universität Freiburg Schweiz», 23), pp. 236.

1 Le volume rassemble neuf communications présentées lors d'un colloque tenu en 2006; elles concernent certains auteurs de premier plan - Prudence, Thomas d'Aquin, Dante et plusieurs textes allemands. Dans le cadre de la rassegna on retiendra plus particulièrement les suivantes. Silvana VECCHIO, Passions de l'âme et péchés capitaux: les ambiguités de la culture médiévale, pp. 45-64, retrace, depuis la patristique jusqu’à Thomas d'Aquin, l'histoire des paradigmes et du statut des passions par rapport aux vices. Bruno BOERNER, Lasterdarstellungen in der mittelalterlichen Monumentalkunst Frankreichs, pp. 65-104. Richard NEWHAUSER, The Capital Vices as Medieval Anthropology, pp. 105-123, sur l'aspiration à la pureté, à laquelle s'oppose le système articulé des vices et des péchés, pollution émanant du désir: modèle hérité du monachisme et dominant au Moyen Age et au-delà. L'index des noms propres complète le volume. 